\title{
The Involvement of Angiotensin Type 1 and Type 2 Receptors in Estrogen-Induced Cell Proliferation and Vascular Endothelial Growth Factor Expression in the Rat Anterior Pituitary
}

\author{
Hanna Lawnicka, ${ }^{1}$ Dorota Ptasinska-Wnuk, ${ }^{2}$ Slawomir Mucha, ${ }^{3}$ \\ Jolanta Kunert-Radek, ${ }^{3}$ Marek Pawlikowski, ${ }^{1}$ and Henryk Stepien ${ }^{1}$ \\ ${ }^{1}$ Department of Immunoendocrinology, Medical University of Lodz, Dr. Sterling 3 Street, 91-425 Lodz, Poland \\ ${ }^{2}$ Department of Endocrinology, The County Hospital of Kutno, 52 Kosciuszki Street, 99-300 Kutno, Poland \\ ${ }^{3}$ Clinic of Endocrinology, Medical University of Lodz, Dr. Sterling 3 Street, 91-425 Lodz, Poland \\ Correspondence should be addressed to Henryk Stepien, hstep@csk.umed.lodz.pl
}

Received 28 October 2011; Accepted 17 December 2011

Academic Editor: Ludwik K. Malendowicz

Copyright () 2012 Hanna Lawnicka et al. This is an open access article distributed under the Creative Commons Attribution License, which permits unrestricted use, distribution, and reproduction in any medium, provided the original work is properly cited.

\begin{abstract}
The aim of our study was to examine the involvement of renin-angiotensin system (RAS) in estrogen-induced lactotropes proliferation and vascular endothelial growth factor (VEGF) expression in rat pituitary. The study was performed on Fisher 344 rats underwent 8-day treatment with diethylstilboestrol (DES). The proliferation index (PCNA) and VEGF expression in pituitary sections were estimated using immunohistochemical methods. Treatment with DES increased the number of PCNA-positive cells, VEGF-positive cells, and VEGF-positive blood vessels in pituitary. Stimulatory effect of estrogen on cell proliferation and VEGF expression in blood vessels was attenuated by losartan, PD123319, and captopril. VEGF immunoreactivity in pituitary cells of DES-treated rats was decreased by AT1 antagonist and not changed by AT2 blocker and ACE inhibitor. Our findings suggest the involvement of RAS in DES-induced cell proliferation and VEGF expression in pituitary. Both the AT1 and AT2 receptors appear to mediate the estrogen-dependent mitogenic and proangiogenic effects in rat pituitary.
\end{abstract}

\section{Introduction}

Estrogens are well known to stimulate, both directly and indirectly, the cellular proliferation in anterior pituitary, and their growth-promoting effects are largely confined to the lactotropes [1-3]. Pituitary lactotropes hyperplasia has been observed in physiological states of estrogen excess, during estrus in several species, and in human pregnancy [4]. Heaney et al. have revealed the cyclic expression of the pituitary tumor transforming gene ( $p t t g)$, basic fibroblast growth factor (bFGF), and vascular endothelial growth factor (VEGF) during the rat estrus cycle, with maximal expression occurring with peak serum estradiol (E2), increased pituitary proliferation and angiogenesis [5]. The functional role of estrogen receptor $(\mathrm{ER} \alpha)$ in cell proliferation, prolactin (PRL) secretion, and expression of some growth factors, including the above-mentioned ones, in pituitary prolactinomas was documented as well [6]. E2 has been found to induce the transforming growth factor-beta 3 (TGF- $\beta 3$ ) secretion from lactotropes. TGF- $\beta 3$ stimulated, in turn, the folliculostellate (FS) cells to release both VEGF and bFGF, the potent mitogen for prolactin- (PRL-) secreting cells [7]. E2 augmented also a level of the key potent proangiogenic cytokine, VEGF, in prolactinoma tumor cell preparations [8]. In vivo, chronic treatment with estrogens resulted in the increased VEGF production and VEGF receptor expression in anterior pituitary of rats [9]. Moreover, tumor formation in estrogeninduced prolactinoma was shown to be associated with the development of the direct arterial blood supply leading the anterior pituitary cells to escape from hypothalamic 
control [10]. All these findings imply the pivotal role of estrogens in the molecular events responsible for lactotrope transformation and following prolactin-secreting adenoma development.

Renin-angiotensin system (RAS) is an essential regulator of the cardiovascular homeostasis and other fundamental biological functions, including hormonal secretion and cellular growth $[11,12]$. Besides the circulating RAS, many organs and tissues are capable of producing angiotensin peptides [13-16]. All the components of RAS have been identified also within pituitary gland, and the main bioactive peptide of RAS, angiotensin II (ang II), has been proved to be synthesized intrapituitary [17]. There are many reports on the interaction between local tissue RAS and estrogens. In the anterior lobe of rat pituitary, the expression of angiotensin receptors (AT) fluctuated during estrous cycle, with the highest binding in diestrus and lowest binding in estrus [18]. Moreover, the number of AT1 receptor subtype and the activity of angiotensin-converting enzyme (ACE) in anterior pituitary of ovariectomized (OVX) rats fell after chronic treatment with E2 $[19,20]$. Nevertheless, longterm exposition of lactotropic cells to the synthetic estrogen, diethylstilboestrol (DES), enhanced the AT1-dependent PRL secretion and strengthened the intracellular calcium mobilization and inositol phosphate generation in response to ang II, suggesting the stimulatory effects of estrogens on the AT1-linked postreceptor mechanisms [21, 22]. Estrogens were also shown to increase the plasma angiotensinogen level and to stimulate the expression of angiotensinogen mRNA in various tissues, including the pituitary gland [23]. Additionally, the release of ang II from hypothalamus has been described to rise in response to estrogen [24]. Next, a chronic exposition to DES led to the upregulation of the AT2 receptor gene transcription and increase in the functional AT2 receptor expression in anterior pituitary of rats [25].

Increasing lines of evidence indicate the important role of RAS in regulation of the cellular growth and angiogenesis within pituitary gland. Ang II and its derivative, ang IV, were found to exert the stimulatory effects on the anterior pituitary cell proliferation both in vitro and in vivo [2628]. These peptides stimulated also the activity of tyrosine kinase (TK) in cells isolated from the estrogen-induced rat pituitary tumors $[29,30]$. In lactosomatotroph GH3 cell culture, ang II, ang III, and ang IV were shown to affect the VEGF secretion [31]. Moreover, local or systemic RAS was suggested to mediate the estrogen-induced vascular changes in the anterior pituitary gland in rodents [52].

The goal of the present study was to investigate the potential involvement of RAS in estrogen-induced cellular proliferation and angiogenesis in anterior pituitary of rats. We performed the experiments using a high estrogenresponsive rat strain, Fisher 344 (F344). F344 is especially susceptible to the estrogens' growth promoting and tumorinducing effects on the pituitary, as chronic treatment of rat with E2 leads to the lactotrope proliferation and following lactotropic tumor formation within a few months [32].

\section{Material and Methods}

2.1. Animals. Four-week-old male Fisher 344 rats, weighing $\sim 60 \mathrm{~g}$ each were used in the experiment. The animals were kept in the controlled conditions of light/darkness $(12 \mathrm{~h} / 12 \mathrm{~h})$ and temperature $\left(23 \pm 2^{\circ} \mathrm{C}\right)$ with standard laboratory food and water available ad libitum.

All procedures were approved by The Local Animal Use and Care Committee (no. Ł/BD/126).

2.2. Induction of Pituitary Cells Hyperplasia. The animals underwent chronic oestrogen treatment using the silastic capsules prepared from $5 \mathrm{~mm}$ long Silastic tubes of $1.57 \mathrm{~mm}$ inner diameter and $2.4 \mathrm{~mm}$ outer diameter (Silastic Laboratory Tubbing, Dow Corning Corporation, USA). These tubes were filled with a saturated solution of diethylstilboestrol (DES; Stilboestrolum, Polfa, Poland) in 96\% ethanol. After evaporation of alcohol, the capsules, containing $8-10 \mathrm{mg}$ of DES each, were sealed with silastic medical adhesive (Silastic Medical Adhesive Silicone Type A, Dow Corning Corporation, USA), protected from light and stored at $4^{\circ} \mathrm{C}$. Such implants were estimated to release $18-45 \mu \mathrm{g} /$ day of DES [1] and to induce the massive hyperplasia of prolactin cells in the strain of rats used in the study.

To induce pituitary lactotropes hyperplasia, the animals underwent the intraperitoneal (i.p.) ketamine (Ketanest, Parke-Davis) anaesthesia (60 mg/kg of body weight) following the subcutaneous (s.c.) implantation of silastic capsules in lumbar region of each rat.

2.3. Experimental Protocol and Preparation of Tissues. Three days after capsules implantation, animals were divided into 5 groups ( 7 rats in each group) and started receiving examined substances as follows:

(i) Group I (control group without capsules; DES-): $0.5 \mathrm{~mL} 0.9 \% \mathrm{NaCl}$, i.p.;

(ii) Group II (control group with capsules; DES+): $0.5 \mathrm{~mL} 0.9 \% \mathrm{NaCl}$, i.p.;

(iii) Group III: Losartan (Merck), $10 \mathrm{mg} / \mathrm{kg}$ of body weight, i.p.;

(iv) Group IV: PD123319 (PD123319 di(trifluoroacetate), Sigma), $1 \mathrm{mg} / \mathrm{kg}$ of body weight, i.p.;

(v) Group V: Captoril (Sigma), $50 \mathrm{mg} / \mathrm{kg}$ of body weight, s.c.

Injections were made twice a day (every $12 \mathrm{~h}$ ) for the following 6 days. Twelve hours after the last injections, all animals were decapitated, pituitary glands were carefully isolated, fixed in $4 \%$ neutral buffered formalin and embedded in paraffin. The $5 \mu \mathrm{m}$ thick sections of the pituitary glands were mounted on normal glass slides for immunohistochemistry.

\subsection{Immunohistochemistry}

2.4.1. Cell Proliferation Study. The determination of the proliferating cell nuclear antigen (PCNA) was applied as an index of cell proliferation. Immunohistochemistry was 
performed using a PC 10 monoclonal antibody (Monoclonal Mouse Anti-Rat Proliferating Cell Nuclear Antigen, Clone PC 10, DakoCytomation). After wax removal, sections were heated in citrate buffer ( $\mathrm{pH} 6.0)$ in a microwave oven $(700 \mathrm{~W}$, $10 \mathrm{~min}$ ) then chilled at room temperature and washed with distilled water and in Tris/ $\mathrm{HCl}$ buffer $(\mathrm{pH}$ 7.4). Sections were then exposed to anti-PCNA PC 10 antibody for 10 minutes and washed again. The visualization of the reaction was achieved using EnVision System-AP (DakoCytomation). The protocol included incubation with Labelled Polymer for $10 \mathrm{~min}$ following washing procedure, incubation with Fast Red solution for $25 \mathrm{~min}$, and subsequent washing with distilled water. The sections were then stained with hematoxylin for $45 \mathrm{~min}$.

2.4.2. VEGF Expression Study. VEGF expression in the anterior pituitary gland cells and vessels was determined using mouse monoclonal antibody $\operatorname{IgG}_{2 \alpha}$ (VEGF (C-1), Santa Cruz Biotechnology). After wax removal, sections were heated in citrate buffer ( $\mathrm{pH} 6.0)$ in a microwave oven $(700 \mathrm{~W}, 5 \mathrm{~min})$ then chilled at room temperature, washed with PBS and incubated with $3 \%$ hydrogen peroxide $\left(\mathrm{H}_{2} \mathrm{O}_{2}\right.$ solution) to block the endogenous peroxidase. The sections were then incubated with anti-VEGF (C-1) immunoglobulin at a dilution of $1: 100$ for $5 \mathrm{~min}$. To intensify the reaction, StreptABComplez/HRP Duet, Mouse/Rabbit (DakoCytomation) kit was used. The protocol included incubation with anti-mouse- $\operatorname{IgG}_{2 \alpha}$ antibodies labeled with peroxidase (POD) for $30 \mathrm{~min}$, washing with PBS, incubation with tetrachloride 3,3'-diaminobenzidine (DAB) solution for $4 \mathrm{~min}$ ( $\mathrm{POD}$ substrate), and washing with running water. The sections were then stained with hematoxylin for $60 \mathrm{~s}$.

2.4.3. Image Analysis. Digital images were acquired from the light microscope (Olympus BX40, Japan) at $\times 200$ magnification via CCD colour camera (CC20P; Videotronic $\mathrm{GmbH}$, Germany) and analyzed using a computer system (MultiScanBase v.8.08; Computer Scanning System, Warsaw, Poland).

The PCNA labeling index (LI) was assessed as a number of PCNA-immunopositive nuclei per 1000 randomly scored anterior pituitary cells in microscopic preparations at $600 \mathrm{x}$ magnification. Minimum 4,000 cells were counted in each slice.

VEGF-immunopositive anterior pituitary cells were assessed as a number of VEGF-immunopositive cells per 1000 randomly scored cells in microscopic preparations at 600x magnification. Moreover, the VEGF-immunopositive cells were classified into one of three categories: the cells with weak, medium, or strong VEGF immunoreactivity. Minimum 4,000 cells were counted in each slice.

VEGF-immunopositive reaction in anterior pituitary vesselswas expressed as the mean number of VEGF-immunopositive vessel sections per microscopic image, counted from 10 microscopic images, at 200x magnification.

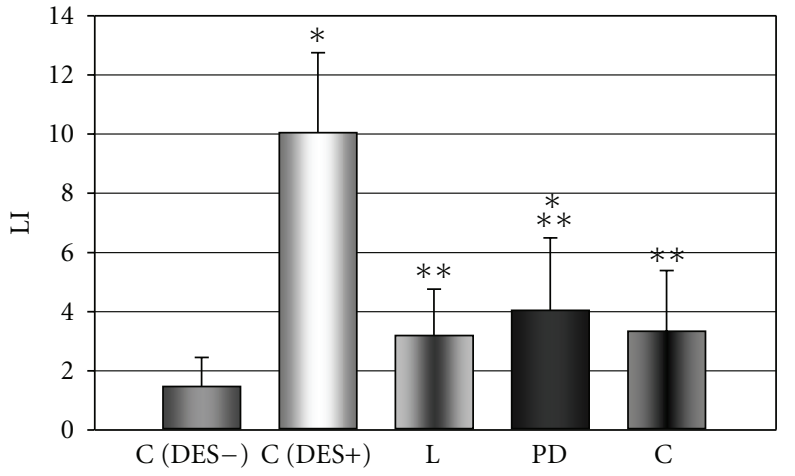

Figure 1: The influence of AT1 receptor antagonist losartan (L), AT2 receptor antagonist PD123319 (PD), and ACE inhibitor captopril (C) on diethylstilboestrol- (DES-) induced increase in number of PCNA immunopositive cells in anterior pituitary of rats. $\mathrm{X} \pm \mathrm{SEM} ;{ }^{*} P<0.05$ versus C (DES-, control DES-untreated group), ${ }^{* *} P<0.05$ versus C (DES+, control DES-treated group), LI: labeling index (the number of PCNA-immunopositive cells per 1000 randomly scattered cells of anterior pituitary).

2.5. Statistical Evaluation. The results are expressed as means \pm SEM. Comparisons of individual groups were evaluated by analysis of variance (ANOVA) following LSD (least difference test) Fisher test. Differences were significant if $P<0.05$.

\section{Results}

The results of the quantitative analysis and the statistical evaluation of these results are presented in Figures 1-5.

The 8-day treatment with DES resulted in a significant elevation in the proliferation index, expressed as a number of the PCNA-immunopositive cells per 1000 randomly scattered cells, in anterior pituitary of rats (Figures 1 and 2(b)). At the same time, the number of PCNA-positive cells was significantly decreased in anterior pituitary of animals receiving the AT1 antagonist losartan, AT2 receptor antagonist PD123319 or ACE inhibitor captopril, comparing to the DES-treated control group (Figures 1, 2(c), 2(d), and 2(e)). These data indicate the inhibitory effects of RAS antagonists on the estrogen-dependent pituitary cell proliferation.

Concomitantly, exposition of rats to DES led to the increased VEGF immunoreactivity in anterior pituitary cells and blood vessels (Figures 3, 4, and 5(b)). Administration of losartan, PD123319, or captopril resulted in a significant decrease in the number of VEGF-positive blood vessels. (Figures 3, 5(c), 5(d) and 5(e)). The number of anterior pituitary cells staining for VEGF diminished in animals receiving only the AT1 antagonist and changed after cotreatment with neither AT2 blocker nor ACE inhibitor (Figures 4, 5(c), 5(d) and 5(e)).

\section{Discussion}

Pituitary gland is the source of various growth factors and cytokines that regulate cellular growth in an autocrine and paracrine manner [33]. Immunohistochemical studies have 


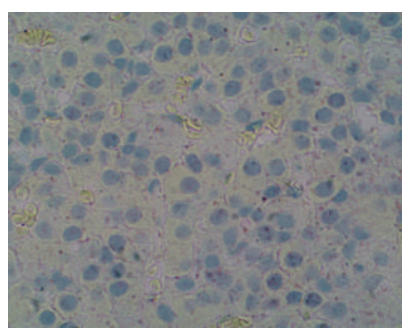

(a)

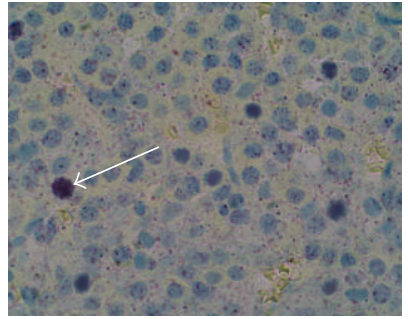

(b)

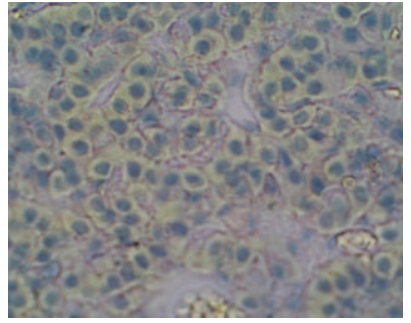

(c)

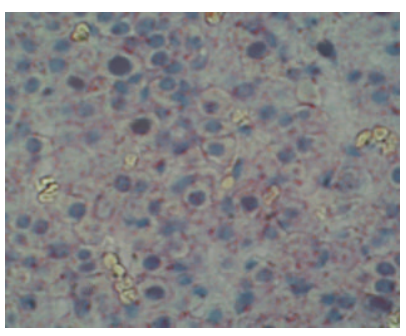

(d)

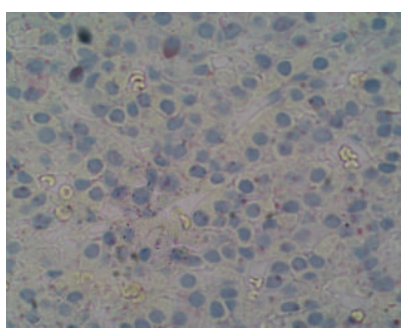

(e)

Figure 2: Immunohistochemical staining for the proliferation cell nuclear antigen (PCNA) in anterior pituitary of rats; (a) control diethylstilboestrol- (DES-) untreated group, (b) control DES-treated group, (c) DES and AT1 blocker (losartan) cotreated group, (d) DES and AT2 blocker (PD12319) cotreated group, and (e) DES and angiotensin converting enzyme inhibitor (captopril) cotreated group. White arrow indicates PCNA-positive cell.

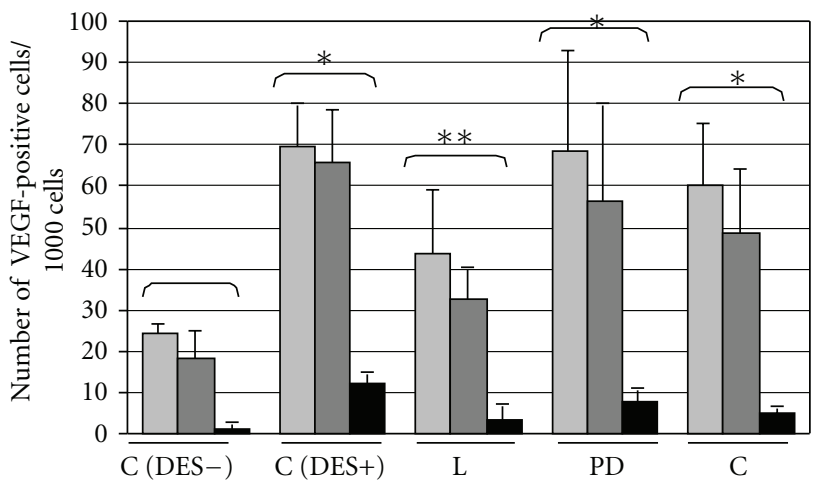

Figure 3: The influence of AT1 receptor antagonist losartan (L), AT2 receptor antagonist PD123319 (PD) and ACE inhibitor captopril (C) on diethylstilboestrol- (DES-) induced increase in number of vascular endothelial growth factor (VEGF) immunopositive cells in anterior pituitary of rats. $\mathrm{X} \pm \mathrm{SEM} ;{ }^{*} P<0.05$ versus $\mathrm{C}$ (DES-, control DES-untreated group), ${ }^{* *} P<0.05$ versus $\mathrm{C}$ (DES+, control DES-treated group). pale gray : weak VEGF immunoreactivity; dark gray : medium VEGF immunoreactivity; black : strong VEGF immunoreactivity.

demonstrated that anterior pituitary cells are also able to express the components of RAS $[34,35]$. At the other hand, angiotensin peptides have been shown to affect the growth of anterior pituitary cells. Ang II and ang IV increased cellular proliferation in the primary culture rat lactotropes [26]. These angiotensin peptides enhanced also BrdU incorporation in anterior pituitary of the ovariectomized female rats in vivo [27]. Furthermore, RAS has been suggested to mediate the estrogen-induced lactotropic cell proliferation and pituitary hyperplasia in rats [28].

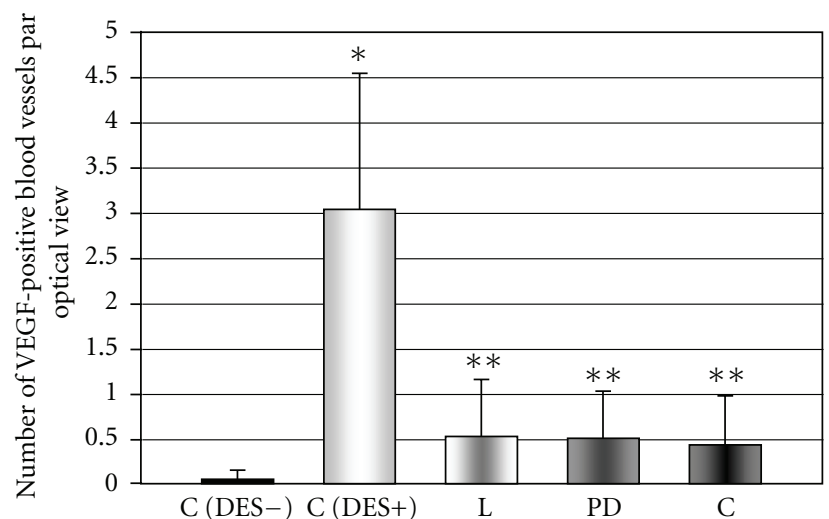

Figure 4: The influence of AT1 receptor antagonist losartan (L), AT2 receptor antagonist PD123319 (PD) and ACE inhibitor captopril (C) on diethylstilboestrol- (DES-) induced increase in number of VEGF immunopositive blood vessels in anterior pituitary of rats. $\mathrm{X} \pm \mathrm{SEM} ;{ }^{*} P<0.05$ versus $\mathrm{C}$ (DES-, control DES-untreated group), ${ }^{* *} P<0.05$ versus $\mathrm{C}$ (DES+, control DES-treated group).

In agreement with the previous reports, chronic exposure to DES significantly increased the number of proliferating cells in anterior pituitary of rats. This mitogenic effect of estrogen was abrogated by the ACE inhibitor, captopril. Moreover, PCNA immunoreactivity was also significantly depressed in pituitaries of animals receiving the AT1 receptor antagonist losartan or AT2 receptor antagonist PD123319, comparing to the DES-treated control group. These findings corroborate with the earlier results concerning the effects of sex steroids on PRL release. Suarez et al. revealed that both the AT1 and AT2 receptor blockers inhibited the ang-II-induced secretion of PRL in rats underwent to 


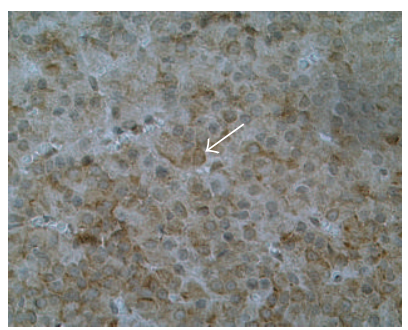

(a)

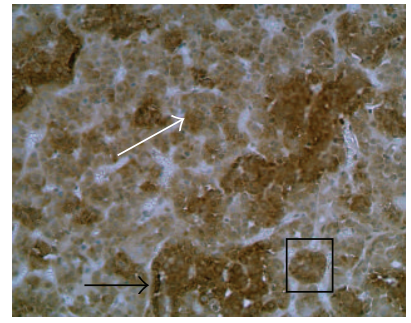

(b)

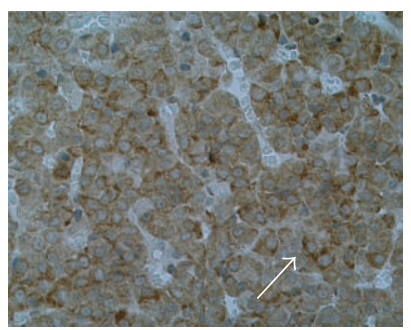

(c)

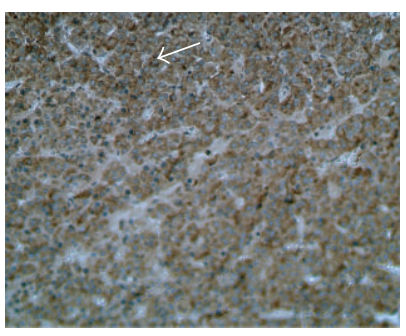

(d)

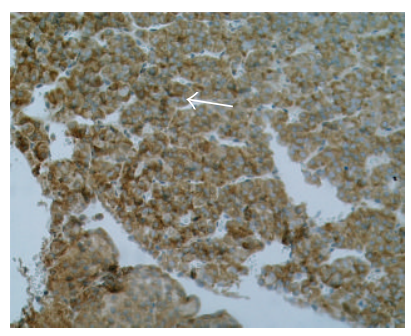

(e)

Figure 5: Immunohistochemical staining for vascular endothelial growth factor (VEGF) in anterior pituitary of rats; (a) control diethylstilboestrol- (DES-) untreated group, (b) control DES-treated group, (c) DES and AT1 blocker (losartan) cotreated group, (d) DES and AT2 blocker (PD12319) co-treated group, and (e) DES and angiotensin converting enzyme inhibitor (captopril) cotreated group. The white arrows indicate the single-VEGF-positive pituitary cell, the black arrow indicates the VEGF immunopositive blood vessel, within the black rectangular: the example isle of VEGF immunopositive cells in rat anterior pituitary.

the combined treatment with DES and progesterone [25]. Surprisingly, in previous in vivo study, neither losartan nor PD123319 decreased the cellular proliferation in DESinduced PRL-secreting tumor in rat, although it was inhibited by angiotensin convertase inhibitor, enalaprilate [28]. This discrepancy may be possibly explained by the resistance of prolactinoma cells to the growth-regulating factors. This is highly probable, that following 12 -week exposure to DES, rat pituitary lactotropes have become autonomous, and thus insensitive to the endogenous angiotensin peptides affecting the growth of unstimulated cells. In the present study, we underwent animals to the only 8-day treatment with DES, thus attempting to prevent the development of such a pituitary cell autonomy. We believe that our experimental model has led us to examine the estrogen-stimulated, but still susceptible to the growth factors anterior pituitary cells, at the initial stages of the estrogen dependent tumorogenesis.

AT1 receptor is well established to be essential for the mitogenic effects of ang II in various tissues and organs [3641]. Moreover, blockade of AT1 signaling reduced tumor growth, angiogenesis, and metastasis in the model of murine sarcoma and fibrosarcoma cells [42]. In contrast, AT2 receptor has been often demonstrated to counteract the AT1-dependent proliferogenic actions [43, 44]. However, ang-II-induced apoptosis of the rat cardiomyocytes was connected with activation of both the AT2 and AT1 receptors [45]. Moreover, AT2 caused constitutive, ligand-independent growth and did not antagonize AT1-mediated cardiomyocytes hypertrophy [46]. Each of these receptors mediated the stimulatory effects of ang II on cellular proliferation and apoptosis in renal glomerular epithelial tissue as well [47]. Such a cooperation of the AT1 and AT2 receptors has been also demonstrated in our present study, as both receptors appeared to mediate the estrogen-induced proliferation of rat anterior pituitary cells.

Pituitary adenoma cells are able to produce the potent angiogenic factor, VEGF, which is possibly involved in the intratumoral blood vessel formation. VEGF was shown to be present in various pituitary tumor cell lines, in primary cultures of pituitary adenomas and in fragments from the human pituitary adenomas obtained at surgery $[8,48]$. The production of this cytokine in lactosomatotroph GH3 cells and in prolactinoma tumor cell preparations was stimulated by estrogens $[8,49,50]$. Ochoa et al. observed also the rapid and transient increase of VEGF in rat anterior pituitary following E2 administration [49]. Estrogen treatment augmented also the VEGF receptor 2 (flk-1/KDR) expression and induced neovascularisation as well as the growth and enlargement of blood vessels in the rat pituitary $[9,51]$.

Similarl to the former data, we observed a significant elevation of the VEGF-immunopositive anterior pituitary cells number and blood vessels density after 8-day exposure of rats to DES. In the pituitaries of estrogen-treated animals, the VEGF-positive cells were distributed in patches surrounding the blood vessels and scattered through all the glandular pituitary (Figure 5(b)). In contrast, only weak staining signals with antibodies to VEGF were detected in a separate, diffusely distributed pituitary cells of untreated control animals (Figure 5(a)). Similar results were obtained by Banerjee et al., who revealed a strong increase in both the intracellular VEGF protein expression and in the VEGFpositive blood vessel density in rat pituitary after 7 days of E2 exposure [9]. At the same time, we noticed a significant fall in the number of VEGF-immunostained cells as well as blood 
vessels in the pituitaries of rats receiving the specific AT1 receptor antagonist losartan. Treatment with ACE inhibitor captopril or AT2 receptor antagonist PD123319 led to the decline in VEGF-positive blood vessel density, whereas it did not affect the VEGF immunostaining in anterior pituitary cells. These results are compatible with our earlier data, showing that losartan is more effective in inhibition of the estrogen-induced pituitary vascular changes than AT2 blocker PD 123319 [52].

The inhibitory effect of losartan suggests that AT1 receptors are involved in the control of VEGF expression, in both pituitary cells and vessels. In contrast, the effects of PD123319, a selective AT2 receptor blocker, and of captopril, an ACE inhibitor, on VEGF expression seem to be confined exclusively to the blood vessels. Recently, it was shown that in human pituitary adenomas AT2 receptor immunopositivity is absent in adenoma cells but it is very strong in blood vessel walls [53]. If the same vascular localization of AT2 receptors concerns also the rat anterior pituitary, this could explain the selective effects of PD123319 on vascular VEGF. The selective effect of captopril on VEGF immunopositivity in blood vessels is more difficult to explain, since this agent inhibits ang II production, and the latter is an agonist of both AT1 and AT2 receptors. However, it should be pointed that inhibition of ang II synthesis leads to the enhanced synthesis of smaller angiotensin peptides via alternative enzymatic pathways [54]. Since the products of ang II degradation have been shown to induce VEGF secretion by pituitary cells, their overproduction possibly offsets the decline of VEGF production resulting from inhibited ang II synthesis. Moreover, concomitant influences of ACE inhibitor on the activity of various enzymes, different from ACE, should be taken into consideration. ACE inhibitors are established to induce kininase II, increasing thereby the tissue bradykinin concentration and affecting angiogenesis via endothelial NO release. Thanks to the presence the thiol radical, captopril is also able to exert the direct influence on vascular growth $[55,56]$.

Regardless the direct proangiogenic activities of angiotensin, the indirect effects of RAS and its inhibitors on the anterior pituitary angiogenesis should not be excluded. The full-length PRL molecule has been shown to possess angiogenic effect in an in vivo assays using the chick chorioallantoic membrane (CAM) [57]. On the other hand, estrogens belong to the potent stimuli of PRL secretion, whereas both ACE inhibitors and angiotensin receptor antagonists have been proved to suppress the DES-induced release of PRL [28]. In this context we can not exclude that inhibition of PRL release following the administration of captopril, losartan, or PD123319 may response, at least in part, for the decrease in number of VEGF-positive vessels in rat anterior pituitary. The identification of mechanisms engaged in the RAS-dependent regulation of angiogenesis in the pituitary gland needs further studies.

The involvement of RAS in regulation of the VEGF-dependent angiogenesis has already been reported with respect to various tissues [58-62]. This is also worth mentioning that both the AT1 and AT2 receptor has been found to participate in proangiogenic effects of angiotensins. The AT1 receptor subtype was implicated in the regulation of angiogenesis during skeletal muscle regeneration, the increase of vessel density in cremaster muscle of rats, the induction of VEGF receptor expression in bovine retinal microcapillary endothelial cells, and the VEGF-dependent angiogenesis in the Matrigel model in mice [63-66]. At the other hand, a higher VEGF expression in the retina of experimental diabetic rats and ang-II-treated rats was partially determined by AT2 receptor activation [67]. The AT2 receptor blockade resulted in an important decrease of the VEGF and its receptor KDR expression in kidney of ang-II-infused rats [68]. Furthermore, the AT2 receptor blockade using PD123319 in animal in vivo models of fibrosarcoma and LL/2 cells carcinoma delayed tumorigenesis by inhibiting malignant cell proliferation and angiogenesis as well [69]. Similar effects were obtained with respect to the anterior pituitary cells. In earlier in vitro study, losartan and PD123319 abrogated the stimulatory influence of ang II on VEGF secretion in GH3 cell culture [31]. Furthermore, the antagonists of both the AT1 and AT2 receptors were also demonstrated to prevent the DES-induced enlargement of blood vessels in anterior pituitary in rodents [52]. Taken together, the present and the previous results imply, that RAS mediates estrogeninduced vascular growth in anterior pituitary, and this process involves the induction and secretion of VEGF via AT1 and AT2 receptors.

Summing up, our results suggest the involvement of RAS in DES-induced cellular proliferation and VEGF expression in anterior pituitary of rat. Both AT1 and AT2 receptors appear to mediate the observed mitogenic and proangiogenic effects of estrogens. Since cellular proliferation and blood vessel formation are indispensable for the tumor development, our study may suggest the participation of RAS in pathogenesis of estrogen-induced PRL-secreting adenoma. Further studies are necessary to extend the reported above properties of RAS antagonists of the to human lactotropic cells.

\section{Acknowledgments}

This work has been supported with the contribution of European Cooperation in the field of Scientific and Technical Research, COST ACTION, Grant no. CM0602 and by Polish Ministry of Science and Higher Education, Grant no. 505-04-001. Hanna Lawnicka and Dorota Ptasinska-Wnuk contributed equally to this work.

\section{References}

[1] J. Wiklund, N. Wertz, and J. Gorski, "A comparison of estrogen effects on uterine and pituitary growth and prolactin synthesis in F344 and Holtzman rats," Endocrinology, vol. 109, no. 5, pp. 1700-1707, 1981.

[2] M. M. Garcia and L. P. Kapcala, "Growth of a microprolactinoma to a macraprolactinoma during estrogen therapy," Journal of Endocrinological Investigation, vol. 18, no. 6, pp. 450-455, 1995. 
[3] P. Yin, K. Kawashima, and J. Arita, "Direct actions of estradiol on the anterior pituitary gland are required for hypothalamusdependent lactotrope proliferation and secretory surges of luteinizing hormone but not of prolactin in female rats," Neuroendocrinology, vol. 75, no. 6, pp. 392-401, 2002.

[4] P. Yin and J. Arita, "Differential regulation of prolactin release and lactotrope proliferation during pregnancy, lactation and the estrous cycle," Neuroendocrinology, vol. 72, no. 2, pp. 72 $79,2000$.

[5] A. P. Heaney, M. Fernando, and S. Melmed, "Functional role of estrogen in pituitary tumor pathogenesis," Journal of Clinical Investigation, vol. 109, no. 2, pp. 277-283, 2002.

[6] H. Lv, C. Li, S. Gui, M. Sun, D. Li, and Y. Zhang, "Effects of estrogen receptor antagonist on biological behavior and expression of growth factors in the prolactinoma MMQ cell line," Journal of Neuro-Oncology, vol. 102, no. 2, pp. 237-245, 2011.

[7] S. Oomizu, K. Chaturvedi, and D. K. Sarkar, "Folliculostellate cells determine the susceptibility of lactotropes to estradiol's mitogenic action," Endocrinology, vol. 145, no. 3, pp. 1473 1480, 2004.

[8] P. Lohrer, J. Gloddek, U. Hopfner et al., "Vascular endothelial growth factor production and regulation in rodent and human pituitary tumor cells in vitro," Neuroendocrinology, vol. 74, no. 2, pp. 95-105, 2001.

[9] S. K. Banerjee, D. K. Sarkar, A. P. Weston, A. De, and D. R. Campbell, "Over expression of vascular endothelial growth factor and its receptor during the development of estrogeninduced rat pituitary tumors may mediate estrogen-initiated tumor angiogenesis," Carcinogenesis, vol. 18, no. 6, pp. 11551161, 1997.

[10] K. A. Elias and R. I. Weiner, "Direct arterial vascularization of estrogen-induced prolactin-secreting anterior pituitary tumors," Proceedings of the National Academy of Sciences of the United States of America, vol. 81, no. 14 I, pp. 4549-4553, 1984.

[11] A. Nguyen Dinh Cat and R. M. Touyz, "A new look at the renin-angiotensin system-focusing on the vascular system," Peptides, vol. 32, no. 10, pp. 2141-2150, 2011.

[12] J. L. Zhuo and X. C. Li, "New insights and perspectives on intrarenal renin-angiotensin system: focus on intracrine/intracellular angiotensin II," Peptides, vol. 32, no. 7, pp. 1551-1565, 2011.

[13] F. Xiao, J. R. Puddefoot, and G. P. Vinson, "The expression of renin and the formation of angiotensin II in bovine aortic endothelial cells," Journal of Endocrinology, vol. 164, no. 2, pp. 207-214, 2000.

[14] P. S. Leung, "Pancreatic RAS," Advances in Experimental Medicine and Biology, vol. 690, pp. 89-105, 2010.

[15] D. T. Dinh, A. G. Frauman, M. Sourial, D. J. Casley, C. I. Johnston, and M. E. Fabiani, "Identification, distribution, and expression of angiotensin II receptors in the normal human prostate and benign prostatic hyperplasia," Endocrinology, vol. 142, no. 3, pp. 1349-1356, 2001.

[16] J. W. Wright and J. W. Harding, "Brain renin-angiotensin-a new look at an old system," Progress in Neurobiology, vol. 95, no. 1, pp. 49-67, 2011.

[17] W. F. Ganong, "Blood, pituitary, and brain renin-angiotensin systems and regulation of secretion of anterior pituitary gland," Frontiers in Neuroendocrinology, vol. 14, no. 3, pp. 233249, 1993.

[18] F. M. Chen, R. Hawkins, and M. P. Printz, "Evidence for a functional, independent brain-angiotensin system: correlation between regional distribution of brain angiotensin receptors, brain angiotensinogen and drinking during the estrous cycle of rats," Experimental Brain Research, vol. 45, no. 4, supplement, pp. 157-168, 1982.

[19] P. D. Carriere, A. de Lean, and J. Gutkowska, "Chronic estradiol treatment decreases angiotensin II receptor density in the anterior pituitary gland and adrenal cortex but not in the mesenteric artery," Neuroendocrinology, vol. 43, no. 1, pp. 49$56,1986$.

[20] A. Seltzer, J. E. B. Pinto, P. N. Viglione et al., "Estrogens regulate angiotensin-converting enzyme and angiotensin receptors in female rat anterior pituitary," Neuroendocrinology, vol. 55, no. 4, pp. 460-467, 1992.

[21] M. P. Platia, K. J. Catt, and G. Aguilera, "Effects of $17 \beta$ estradiol on angiotensin II receptors and prolactin release in cultured pituitary cells," Endocrinology, vol. 119, no. 6, pp. 2768-2772, 1986.

[22] A. G. Iglesias, G. Diaz-Torga, V. Lux-Lantos, C. Libertun, and D. Becu-Villalobos, "Calcium influx and intracellular stores in angiotensin II stimulation of normal and hyperplastic pituitary cells," American Journal of Physiology, vol. 277, no. 3, pp. E455-E463, 1999.

[23] D. P. Healy, M.-Q. Ye, L. X. Yuan, and B. S. Schachter, "Stimulation of angiotensinogen mRNA levels in rat pituitary by estradiol," American Journal of Physiology, vol. 263, no. 2, pp. E355-E361, 1992.

[24] M. I. Phillips, H. Wang, B. Kimura, M. Rejtman, P. Koduri, and S. P. Kalra, "Dynamic changes in hypothalamic angiotensin II levels and release in association with progesterone-induced luteinizing hormone surge," Endocrinology, vol. 132, no. 4, pp. 1637-1642, 1993.

[25] C. Suarez, G. Díaz-Torga, A. González-Iglesias, C. Cristina, and D. Becu-Villalobos, "Upregulation of angiotensin II type 2 receptor expression in estrogen-induced pituitary hyperplasia," American Journal of Physiology, Endocrinology and Metabolism, vol. 286, no. 5 49-5, pp. E786-E794, 2004.

[26] M. Pawlikowski and J. Kunert-Radek, "Angiotensin IV stimulates the proliferation of rat anterior pituitary cells in vitro," Biochemical and Biophysical Research Communications, vol. 232, no. 2, pp. 292-293, 1997.

[27] D. Ptasinska-Wnuk, J. Kunert-Radek, and M. Pawlikowski, "Angiotensins II and IV stimulate the rat anterior pituitary cell proliferation independently of the AT1 receptor subtype," Neuroendocrinology Letters, vol. 24, no. 6, pp. 397-400, 2003.

[28] M. Pawlikowski, S. Mucha, J. Kunert-Radek, H. Stępień, H. Pisarek, and A. Stawowy, "Is estrogen-induced pituitary hiperplasia and hiperprolactinemia mediated by angiotensin II," in Tissue Rennin-Angiotensin System, A. K. Mukhopadhyay and K. M. Raizada, Eds., pp. 397-400, Plenum Press, 1995.

[29] A. Lachowicz-Ochedalska, E. Rebas, J. Kunert-Radek, M. C. Fournie-Zaluski, and M. Pawlikowski, "Angiotensins II and IV stimulate the activity of tyrosine kinases in estrogen-induced rat pituitary tumors," Biochemical and Biophysical Research Communications, vol. 297, no. 4, pp. 931-933, 2002.

[30] E. Rębas, A. Lachowicz-Ochędalska, and M. Pawlikowski, "Angiotensin IV stimulates the activity of tyrosine kinases in rat anterior pituitary gland acting via AT1-like receptors?" Journal of Physiology and Pharmacology, vol. 55, no. 1, pp. 107$111,2004$.

[31] D. Ptasińska-Wnuk, H. Ławnicka, J. Fryczak, J. KunertRadek, and M. Pawlikowski, "Angiotensin peptides regulate angiogenic activity in rat anterior pituitary tumour cell cultures," Endokrynologia Polska, vol. 58, no. 6, pp. 478-486, 2007.

[32] M. Pastorcic, A. De, N. Boyadjieva, W. Vale, and D. K. Sarkar, "Reduction in the expression and action of transforming 
growth factor $\beta 1$ on lactotropes during estrogen-induced tumorigenesis in the anterior pituitary," Cancer Research, vol. 55, no. 21, pp. 4892-4898, 1995.

[33] D. Ray and S. Melmed, "Pituitary cytokine and growth factor expression and action," Endocrine Reviews, vol. 18, no. 2, pp. 206-228, 1997.

[34] E. Vila-Porcile and P. Corvol, "Angiotensinogen, prorenin, and renin are co-localized in the secretory granules of all glandular cells of the rat anterior pituitary: an immunoultrastructural study," Journal of Histochemistry and Cytochemistry, vol. 46, no. 3, pp. 301-311, 1998.

[35] E. Vila-Porcile, A. Barret, and P. Corvol, "Secretion of renin-angiotensin system (RAS) components by normal and tumoral lactotropes: a comparative study using reverse hemolytic plaque assay (RHPA) and immunoelectron micros-copy," Journal of Histochemistry and Cytochemistry, vol. 48, no. 12, pp. 1691-1704, 2000.

[36] A. Zhang, G. Ding, S. Huang et al., "c-Jun $\mathrm{NH}_{2}$-terminal kinase mediation of angiotensin II-induced proliferation of human mesangial cells," American Journal of Physiology, Renal Physiology, vol. 288, no. 6, pp. F1118-F1124, 2005.

[37] S. Louis, L. Saward, and P. Zahradka, "Both AT1 and AT2 receptors mediate proliferation and migration of porcine vascular smooth muscle cells," American Journal of Physiology, Heart and Circulatory Physiology, vol. 301, no. 3, pp. H746H756, 2011.

[38] G. Wennemuth and G. Aumiller, "Angiotensin II-mediated calcium signals and mitogenesis in human prostate stromal cell line hPCPs," British Journal of Pharmacology, vol. 144, no. 1, pp. 3-10, 2005.

[39] Y. J. Zhang, X. S. Yang, P. S. Wu et al., "Effects of angiotensin II and losartan on the growth and proliferation of hepatic stellate cells," Di Yi Jun Yi Da Xue Xue Bao, vol. 23, no. 3, pp. 219-227, 2003.

[40] Y. Nagashio, H. Asaumi, S. Watanabe et al., "Angiotensin II type 1 receptor interaction is an important regulator for the development of pancreatic fibrosis in mice," American Journal of Physiology, Gastrointestinal and Liver Physiology, vol. 287, no. 1, pp. G170-G177, 2004.

[41] K. E. Rodgers, S. Xiong, R. Steer, and G. S. DiZerega, "Effect of angiotensin II on hematopoietic progenitor cell proliferation," Stem Cells, vol. 18, no. 4, pp. 287-294, 2000.

[42] M. Fujita, I. Hayashi, S. Yamashina, M. Itoman, and M. Majima, "Blockade of angiotensin AT1a receptor signaling reduces tumor growth, angiogenesis, and metastasis," Biochemical and Biophysical Research Communications, vol. 294, no. 2, pp. 441-447, 2002.

[43] J. Zimpelmann and K. D. Burns, "Angiotensin II AT2 receptors inhibit growth responses in proximal tubule cells," American Journal of Physiology, Renal Physiology, vol. 281, no. 2, pp. F300-F308, 2001.

[44] M. De Gasparo, K. J. Catt, T. Inagami, J. W. Wright, and T. Unger, "International union of pharmacology. XXIII. The angiotensin II receptors," Pharmacological Reviews, vol. 52, no. 3, pp. 415-472, 2000.

[45] I. Goldenberg, E. Grossman, K. A. Jacobson, V. Shneyvays, and A. Shainberg, "Angiotensin II-induced apoptosis in rat cardiomyocyte culture: a possible role of AT1 and AT2 receptors," Journal of Hypertension, vol. 19, no. 9, pp. 16811689, 2001.

[46] A. D'Amore, M. J. Black, and W. G. Thomas, “The angiotensin II type 2 receptor causes constitutive growth of cardiomyocytes and does not antagonize angiotensin II type 1 receptormediated hypertrophy," Hypertension, vol. 46, no. 6, pp. 1347 1354, 2005.
[47] Z. Cao, D. J. Kelly, A. Cox et al., "Angiotensin type 2 receptor is expressed in the adult rat kidney and promotes cellular proliferation and apoptosis," Kidney International, vol. 58, no. 6, pp. 2437-2451, 2000.

[48] P. Viacava, M. Gasperi, G. Acerbi et al., "Microvascular density and vascular endothelial growth factor expression in normal pituitary tissue and pituitary adenomas," Journal of Endocrinological Investigation, vol. 26, no. 1, pp. 23-28, 2003.

[49] A. L. Ochoa, N. A. Mitchner, C. D. Paynter, R. E. Morris, and N. Ben-Jonathan, "Vascular endothelial growth factor in the rat pituitary: differential distribution and regulation by estrogen," Journal of Endocrinology, vol. 165, no. 2, pp. 483492, 2000.

[50] S. K. Banerjee, M. N. Zoubine, T. M. Tran, A. P. Weston, and D. R. Campbell, "Overexpression of vascular endothelial growth factor164 and its co-receptor neuropilin-1 in estrogeninduced rat pituitary tumors and GH3 rat pituitary tumor cells," International Journal of Oncology, vol. 16, no. 2, pp. 253260, 2000.

[51] M. Pawlikowski, J. Kunert-Radek, M. Grochal, K. Zieliński, and A. Kulig, "The effects of somatostatin analog octreotide on diethylstilboestrol-induced prolactin secretion, cell proliferation and vascular changes," Histology and Histopathology, vol. 12, pp. 991-994, 1997.

[52] M. Pawlikowski, M. Grochal, A. Kulig et al., "The effect of angiotensin II receptor antagonists on diethylstilbestrolinduced vascular changes in the rat anterior pituitary gland: a quantitative evaluation," Histology and Histopathology, vol. 11, no. 4, pp. 909-913, 1996.

[53] M. Pawlikowski, "Immunohistochemical detection of angiotensin receptors AT1 and AT2 in normal rat pituitary gland, estrogen-induced rat pituitary tumor and human pituitary adenomas," Folia Histochemica et Cytobiologica, vol. 44, no. 3, pp. 173-177, 2006.

[54] T. Unger, "The role of the renin-angiotensin system in the development of cardiovascular disease," American Journal of Cardiology, vol. 89, no. 2, pp. 3A-9A, 2002.

[55] O. V. Volpert, W. F. Ward, M. W. Lingen et al., "Captopril inhibits angiogenesis and slows the growth of experimental tumors in rats," Journal of Clinical Investigation, vol. 98, no. 3, pp. 671-679, 1996.

[56] A. Molteni, W. F. Ward, C. H. Ts'ao et al., "Cytostatic properties of some angiotensin I converting enzyme inhibitors and of angiotensin II type I receptor antagonists," Current Pharmaceutical Design, vol. 9, no. 9, pp. 751-761, 2003.

[57] A. M. Corbacho, G. Martínez de la Escalera, and C. Clapp, "Roles of prolactin and related members of the prolactin/growth hormone/placental lactogen family in angiogenesis," Journal of Endocrinology, vol. 173, no. 2, pp. 219-238, 2002.

[58] C. Pupilli, L. Lasagni, P. Romagnani et al., "Angiotensin II stimulates the synthesis and secretion of vascular permeability factor/vascular endothelial growth factor in human mesangial cells," Journal of the American Society of Nephrology, vol. 10, no. 2, pp. 245-255, 1999.

[59] H. Yoshiji, R. Noguchi, Y. Ikenaka, K. Kaji, Y. Aihara, and H. Fukui, "Impact of renin-angiotensin system in hepatocellular carcinoma," Current Cancer Drug Targets, vol. 11, no. 4, pp. 431-441, 2011.

[60] A. Otani, H. Takagi, H. Oh et al., "Angiotensin II-stimulated vascular endothelial growth factor expression in bovine retinal pericytes," Investigative Ophthalmology and Visual Science, vol. 41, no. 5, pp. 1192-1199, 2000. 
[61] M. M. de Resende, T. J. Stodola, and A. S. Greene, "Role of the renin angiotensin system on bone marrow-derived stem cell function and its impact on skeletal muscle angiogenesis," Physiological Genomics, vol. 42, no. 3, pp. 437-444, 2010.

[62] Y. D. Li, E. R. Block, and J. M. Patel, "Activation of multiple signaling modules is critical in angiotensin IV-induced lung endothelial cell proliferation," American Journal of Physiology, Lung Cellular and Molecular Physiology, vol. 283, no. 4, pp. L707-L716, 2002.

[63] S. L. Amaral, R. J. Roman, and A. S. Greene, "Renin gene transfer restores angiogenesis and vascular endothelial growth factor expression in Dahl S rats," Hypertension, vol. 37, no. 2, pp. 386-390, 2001.

[64] D. H. Munzenmaier and A. S. Greene, "Opposing actions of angiotensin II on microvascular growth and arterial blood pressure," Hypertension, vol. 27, no. 3, pp. 760-765, 1996.

[65] L. M. Bellamy, A. P. W. Johnston, M. De Lisio, and G. Parise, "Skeletal muscle-endothelial cell cross talk through angiotensin II," American Journal of Physiology, Cell Physiology, vol. 299, no. 6, pp. C1402-C1408, 2010.

[66] R. Tamarat, J. S. Silvestre, M. Duriez, and B. I. Levy, "Angiotensin II angiogenic effect in vivo involves vascular endothelial growth factor- and inflammation-related pathways," Laboratory Investigation, vol. 82, no. 6, pp. 747-756, 2002.

[67] X. Zhang, M. Lassila, M. E. Cooper, and Z. Cao, "Retinal expression of vascular endothelial growth factor is mediated by angiotensin type 1 and type 2 receptors," Hypertension, vol. 43, no. 2, pp. 276-281, 2004.

[68] B. Rizkalla, J. M. Forbes, M. E. Cooper, and Z. Cao, "Increased renal vascular endothelial growth factor and angiopoietins by angiotensin II infusion is mediated by both AT1 and AT2 receptor," Journal of the American Society of Nephrology, vol. 14, no. 12, pp. 3061-3071, 2003.

[69] N. Clere, I. Corre, S. Faure et al., "Deficiency or blockade of angiotensin II type 2 receptor delays tumorigenesis by inhibiting malignant cell proliferation and angiogenesis," International Journal of Cancer, vol. 127, no. 10, pp. 22792291, 2010. 


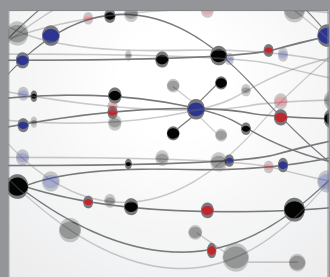

The Scientific World Journal
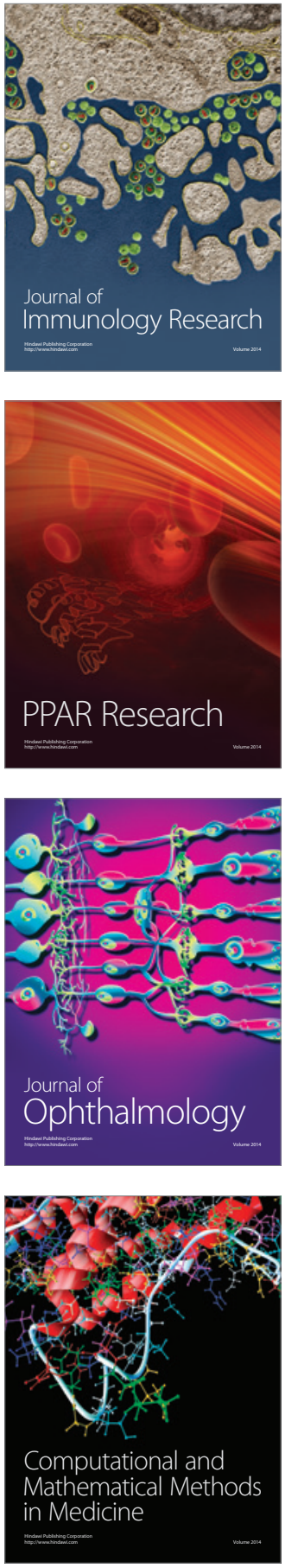

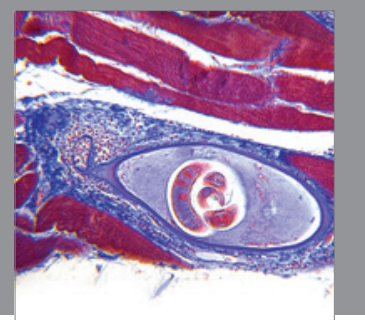

Gastroenterology

Research and Practice
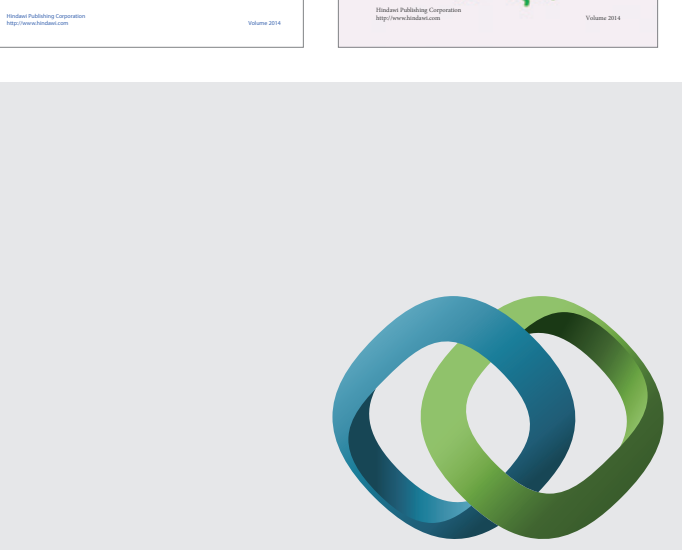

\section{Hindawi}

Submit your manuscripts at

http://www.hindawi.com
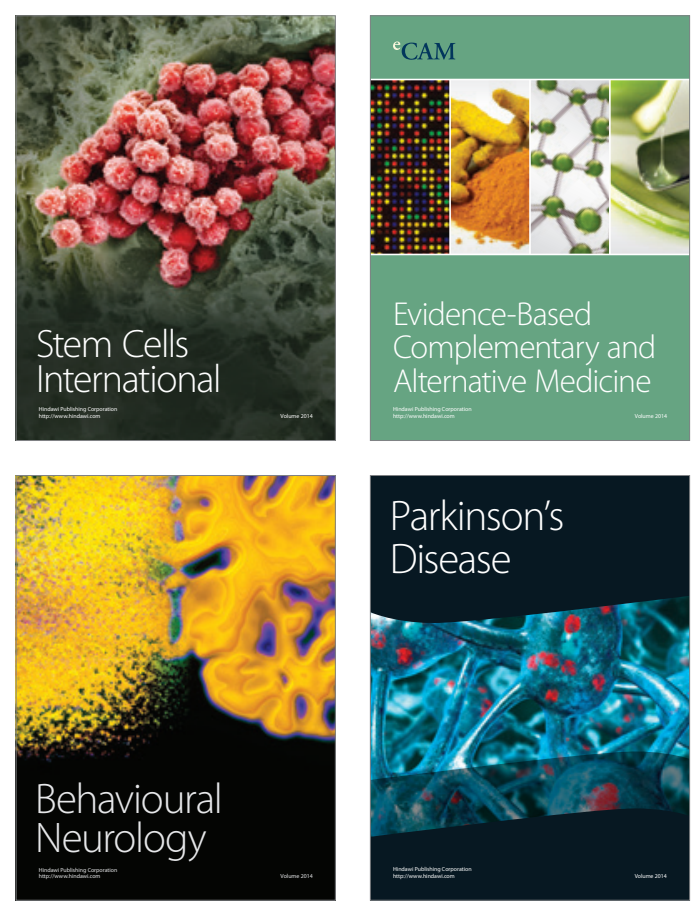

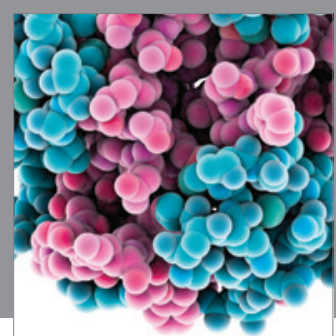

Journal of
Diabetes Research

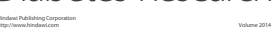

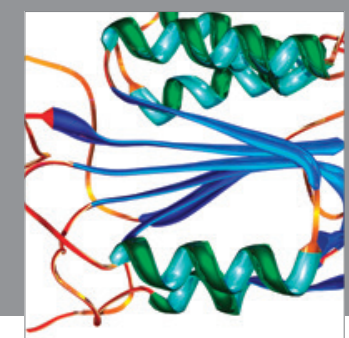

Disease Markers
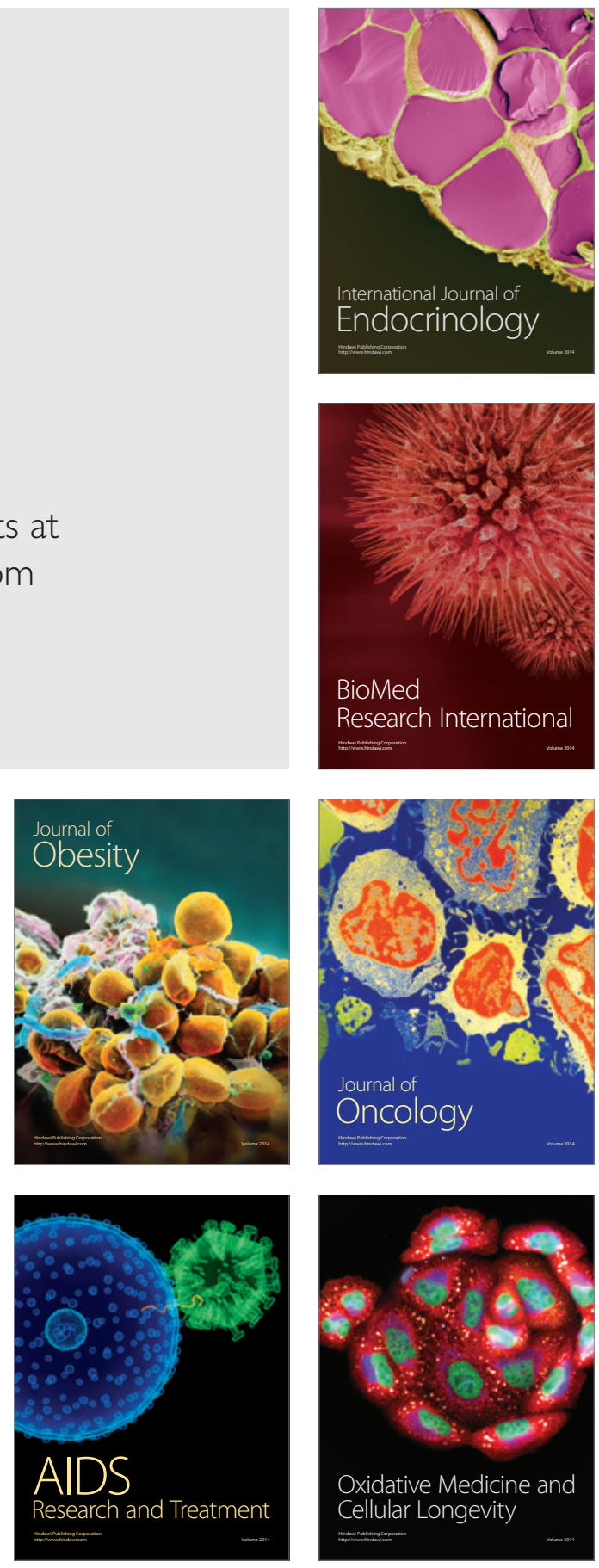